very small creatures the hind wings of which are vestigial or absent. The tegmina occur in probably all the species in two forms, macropterous and brachypterous, although both these types have not yet been found in all cases.

\section{The Solar Apex}

Mr. O. R. WAIKEy has examined the literature on the position of the solar apex (Mon. Not. Roy. Astro. Soc., 106, No. 4 ; 1946). Table 1 shows the marked divergences in the positions determined from 1933 to 1941. Mr. Walkey uses as his basis Moore's "Catalogue of Radial Velocities" (Pub. Lick Obs., 18; 1932) and Boss' "General Catalogue" (Carnegie Pub., No. 468 ; 1937). It is suggested that the divergences just referred to may be partly due to rotation in a probable local cluster which leavens the allowance made for galactic rotation-a view to which some support is given by the increased declination in the apex with increased magnitude of the stars used. Mr. Walkey believes that our ignorance of the actual peculiar motions of the stars, and the consequent assumptions required to fill this gap in our knowledge, may undermine "the refined mathematical edifice built thereon". Using the two catalogues mentioned, he considers the sense alone of their respective motions, whether reflecting "pro"-solar motion, or the reverse-"con". In this way he by-passes assumptions for distance (for cross-motions), etc., and also the general assignment of arbitrary limits for acceptable motions. A full explanation of the method appears in the paper, to which reference must be made for details of the method; Mr. Walkey states that the method is a development of that mentioned by Russell, Dugan and Stewart in "Astronomy", vol. 2. As a result of his investigation, involving 40,720 star motions, Walkey's conclusions are as follow: position of solar apex, 1900.0; R.A. $270 \cdot 2^{\circ} \pm 0 \cdot 3^{\circ}$, Dec. $+28 \cdot 7 \pm 0 \cdot 5^{\circ}$. The solar velocity of approach was found to be $20.5 \pm$ $0.6 \mathrm{~km}$. $/ \mathrm{sec}$., its galactic planar component being $19.0 \mathrm{~km} . / \mathrm{sec}$. and the normal $7.75 \mathrm{~km}$./sec.

\section{Metal Caps for Test-tubes}

We have received from Messrs. Oxo, Ltd. (Thames House, Queen St. Place, E.C.4), samples of metal caps for test-tubes. These caps have been used for some time in their laboratories, and Messrs. Oxo offer to supply them free of charge to other laboratories which ask for them. The caps are intended as a substitute for cotton wool plugs, and Messrs. Oxo claim for them the following advantages : test-tubes of media fitted with the caps remain sterile for long periods; there are no fibres to contaminate the media; tubes fitted with the caps can be sealed with 'Cellophane'; the caps can be labelled with an ordinary pencil and this labelling withstands autoclaving; they are easily removed and replaced and do not stick to the mouths of the tubes; the caps last a long time and can be cleaned by boiling in 0.5 per cent caustic soda, followed by rinsing and drying. The caps appear to be made of an aluminium alloy and are supplied in three sizes to fit standard test-tubes with outside diameters of $\frac{5}{8}, \frac{3}{4}$ and 1 in.

\section{Rare and Historic Maps}

Mr. Francis Edwards, 83 Marylebone High Street, London, W.1, has issued a catalogue (No. 692) of maps and atlases of the British Isles from the sixteenth to the nineteenth centuries which contains several items of unusual interest. There is a first edition of Camden's "Britannia" with 57 doublepage maps, and also a copy of Collins' "Coasting Pilot" of 1693 with 48 maps. Perhaps more noteworthy are several copies of different editions of Speed's atlas, including the rare fully-coloured one, and a first edition of Saxton's atlas of England and Wales. The catalogue also lists a copy of that rarest of all sea atlases, "Arcano del Mare" of Robert Dudley, Duke of Northumberland, with 133 maps, and plans and diagrams.

\section{Geology in Scotland: Swiney Lectures}

THe first half of the course of Swiney Lectures on geology are being delivered (December 6-17) by Dr. Douglas A. Allan, director of the Royal Scottish Museum, at the Museum itself in Chambers Street, Edinburgh. The general title covering the twelve lectures is "The Geology and Scenery of Scotland". This is the first time that Swiney Lectures, which are under the direction of the British Museum (Natural History), have been given outside London, and $\mathbf{M r}$. N. B. Kinnear, director of the Museum, presided at the opening lecture. The last six lectures will be delivered at the same place at 5.30 p.m. on Mondays, Wednesdays and Fridays during January 17-28, 1949.

\section{Announcements}

Prof. Ernst Gaumane, of the Federal Technical College, Zurich, has been elected correspondant for the Section of Botany of the Paris Academy of Sciences, in succession to Dr. A. F. Blakeslee, who has been elected a foreign associate of the Academy.

Prof. E. G. CULLWICK, director of the Electrical Research Division, Research Defence Board, Ottawa, will be the first occupant of the new Watson-Watt chair of electrical engineering at University College, Dundee.

Dr. J. L. B. Cooper, of the Department of Mathematics, Birkbeck College, University of London, has been appointed to the University readership in mathematics tenable at the College.

A SERIES of four sessions on the "Educational and Social Significance of the Land" has been arranged by the Association of Agrieulture and the University of London Institute of Education, to be held at the latter's headquarters in Malet Street, London, W. C.1. The first session has already been held and the remaining three will be at 10 a.m. on December 11, and February 5 and 19. At each session two lectures of one hour's duration will be delivered, and emphasis will be laid on teaching methods in the middle forms of secondary schools. Admission is 1s. per session or 2s. $6 d$. for all four, and further details may be had on application to the general secretary, Association of Agriculture, Abbey House, Victoria Street, London, S.W.I.

A sERIEs of three Christmas Lectures, especially adapted for a juvenile audience of from twelve to seventeen years of age, will be given in the Royal Photographic Society's House, at 16 Princes Gate, London, S.W.7, on December 29, 30 and 31, 1948. A special house exhibition, comprising Nature sub. jects, is being arranged by Mr. Oliver Pike to coincide with the lectures. The lecturers and subjects will be as follows: "The Chemistry of the Process", by Dr. H. Baines ; "Formation of the Image and Making the Negative and Print", Part I, by Mr. K. H. Gaseltine, and Part 2 the next day. Admission will be free but by ticket only, obtainable on application to the Secretary of the Society at the above address. 